\title{
Expression Profiles of Reproduction- and Thyroid Hormone-Related Transcripts in the Brains of Chemically-Induced Intersex Frogs
}

\author{
V.S. Langlois P. Duarte-Guterman V.L. Trudeau \\ Centre for Advanced Research in Environmental Genomics, Department of Biology, University of Ottawa, \\ Ottawa, Ont., Canada
}

\author{
Key Words \\ 5-alpha reductase Aromatase $\cdot 5$-beta reductase . \\ Fadrozole Finasteride $\cdot$ Receptor $\cdot$ Thyroid hormone \\ Xenopus tropicalis
}

\begin{abstract}
Endocrine disrupting chemicals can induce intersex animals in amphibians and fish. Our previous study in frogs demonstrated that chemically-induced intersex animals can display different hepatic profiles of transcript levels than normal animals. In this study, we extend the observations to the developing frog brain. We investigated the effects of finasteride and fadrozole known to induce female- and male-biased sexual development on Silurana tropicalis brain mRNA levels. Real-time RT-PCR analysis of transcript levels of sex steroidand thyroid hormone-related genes in the brain demonstrated that in finasteride-induced intersex animals, the mRNA levels of aromatase, estrogen receptor $\alpha$, thyroid hormone receptor $\beta$ and deiodinase type 3 were higher compared to both control males and females. Furthermore, finasteride-induced intersex animals expressed higher mRNA levels of both androgen receptor and estrogen receptor $\beta$ compared to control females and to control males, respectively. Furthermore, fadrozole did not affect any of the genes analyzed in the brain but was effective at reducing aromatase activity. Intersex animals display different profiles of
\end{abstract}

transcript levels in the brain whether the intersex condition was induced by an anti-androgen or anti-estrogen treatment. Finally, we conclude that a complex relationship exists between thyroid hormone-responsive genes and androgen status in frogs.

Copyright $\odot 2011$ S. Karger AG, Basel

There is evidence that endocrine disrupting chemicals (EDCs) can upset sexual development and induce intersex (presence of testicular oocytes) phenotypes in wild amphibian populations [Hayes et al., 2003; McCoy et al., 2008]. Recent studies have shown that exposure to antiandrogen (e.g., finasteride) and anti-estrogen (e.g., fadrozole) treatments can alter amphibian gonadal differentiation and induce the intersex condition [Duarte-Guterman et al., 2009; Olmstead et al., 2009]. Synthesis of estrogens and androgens proceeds largely through similar enzymatic steps; however, the final step of the biosynthesis requires the action of aromatase (cyp19) and steroid $5 \alpha$ - and $5 \beta$-reductases (srd5alpha type 1,2, 3 and srd5beta), respectively. In a previous study from our lab-

V.S.L. and P.D.-G. contributed equally to this project and should be considered co-first authors.

\section{KARGER \\ Fax +4161306 1234 \\ E-Mail karger@karger.ch}

www.karger.com
C 2011 S. Karger AG, Basel

$1661-5425 / 11 / 0051-0026 \$ 38.00 / 0$

Accessible online at:

www.karger.com/sxd
Valérie S. Langlois

Department of Chemistry and Chemical Engineering

Royal Military College of Canada

P.O. Box 17 000, Stn Forces, Kingston, ON K7K 7B4 (Canada)

Tel. +1 613541 5010, ext. 3621, Fax +1 613542 9489, E-Mail valerie.langlois@ rmc.ca 
oratory, we obtained intersex animals after blocking androgen or estrogen synthesis [Duarte-Guterman et al., 2009]. To block the androgen pathway, we used finasteride, a synthetic srd5alpha (type 1 and 2) inhibitor used to treat prostate cancer and benign prostatic hyperplasia in humans (17 $\beta$-[N-tert-butylcarbamoyl]-4-aza-5 $\alpha$-androst-1-en-3-one; MK-906) [Stoner, 1990]; while estrogen synthesis was blocked using fadrozole (4-(5,6,7,8-tetrahydroimidazo[1,5-a]pyridin-5-yl)benzonitrile monohydrochloride; CGS 16949A), a specific inhibitor of cyp19 in frogs [Langlois et al., 2010] and other vertebrates [e.g., Steele et al., 1987; Ankley et al., 2002]. We demonstrated previously that intersex animals obtained after chronic exposure to either finasteride or fadrozole result in differential hepatic profiles of transcript levels of sex steroidand thyroid hormone (TH)-related genes in Silurana (Xenopus) tropicalis when compared to normal males and females [Duarte-Guterman et al., 2009]. Therefore, the aim of this study was to investigate if the brains of S. tropicalis were also affected by these steroidogenic inhibitors and if the intersex animals exhibit different mRNA level patterns compared to normal males and females.

Sex steroids are involved in gonadal differentiation in frogs [Hayes, 1998]; however, much less is known about their roles in brain development and sexual differentiation. In most vertebrates, sex steroids are responsible for sexual differentiation of neural structures and reproductive behaviors [fish, reviewed in Diotel et al., 2010; birds, reviewed in Hutchison and Steimer, 1981; mammals, reviewed in Morris et al., 2004]. Furthermore, in the brain of birds, while $17 \beta$-estradiol and $5 \alpha$-dihydrotestosterone are involved in sexual behaviors, the $5 \beta$-reduction of testosterone into $5 \beta$-dihydrotestosterone was suggested to be involved in the control of brain sensitivity to sex steroids [Hutchison and Steimer, 1981]. In addition, the developing vertebrate brain is a target of THs (thyroxine [T4] and triiodothyronine [T3]). Deficiency in THs can result in extreme defects in brain development such as cell migration and differentiation of both neuronal and glial cells [reviewed in Bernal et al., 2003]. There is also evidence of cross-talk between the developing reproductive and $\mathrm{TH}$ axes to control transcription in the frog brain [Hogan et al., 2007; Duarte-Guterman and Trudeau, 2010].

EDCs can detrimentally affect neuroendocrine control mechanisms and sexual behavior in vertebrates [Martiniuk et al., 2006; Mennigen et al., 2008; Ottinger et al., 2009; Hayes et al., 2010]. Therefore, one objective of this study was to identify genes in the brain that are susceptible to change if sex steroid levels are chemically altered in developing frogs. The target genes that were cho- sen included those involved in the synthesis and action of sex steroids and THs. A second objective of this project was to determine the profiles of transcript levels in the brain of S. tropicalis intersex animals. We used finasteride as a model anti-androgen and fadrozole as a model anti-estrogen compound to obtain intersex tadpoles at metamorphic climax. Apart from our previous liver study [Duarte-Guterman et al., 2009], the intersex pathology has not been further characterized in the literature. We hypothesize that chemically-induced intersex $S$. tropicalis will express different brain mRNA profiles compared to males and females (both control and exposed) and that these profiles will vary depending on the mode of action of the chemical.

\section{Material and Methods}

\section{Animals and Exposures}

Tadpoles of Silurana tropicalis were exposed to finasteride (25 $\mu \mathrm{M})$ dissolved in ethanol (EtOH; 0.05\% final concentration) and fadrozole $(2 \mu \mathrm{M})$ dissolved in water from Nieuwkoop-Faber (NF [Nieuwkoop and Faber, 1994]) stage 12 until stage 60, along with their respective controls (EtOH and water controls) as previously described in Duarte-Guterman et al. [2009]. At the end of the exposure, brains were dissected and stored at $-80^{\circ} \mathrm{C}$. Homogenization and disruption of individual brain samples was achieved using an MM301 Mixer Mill (Retsch, Newton, Pa., USA) at $20 \mathrm{~Hz}$ for 3 min. Total RNA was obtained using the RNeasy Micro Kit (Qiagen, Mississauga, Ont., Canada). Isolated RNA was resuspended in RNase-free water and concentrations of RNA were determined using the NanoDrop-1000 spectrophotometer (NanoDrop Technologies Inc.). Total cDNA was prepared from $1 \mu \mathrm{g}$ of total RNA and $0.2 \mu \mathrm{g}$ random hexamer primers using Superscript II reverse transcriptase (Invitrogen). Sex of the animals (male, female or intersex) was based on the gonadal analysis previously described in Duarte-Guterman et al. [2009]. Intersex was defined as the presence of at least one oocyte in the testes. Intersex samples displayed a low number of oocytes ( $<10$ oocytes) which allowed the comparison within and between finasteride and fadrozole treatments. Gonadal histology demonstrated that 27\% male, 53\% female and $20 \%$ intersex individuals were produced after finasteride treatment, and 55\% male, 30\% female and 15\% intersex individuals were obtained after fadrozole treatment.

\section{Real-Time RT-PCR}

Real-time RT-PCR assays were performed in a MX3005P realtime polymerase chain reaction system (Stratagene, La Jolla, Calif., USA). The transcript levels of cyp19, srd5alpha1, srd5alpha2, srd5alpha3, srd5beta, estrogen receptor $\alpha$ (eralpha), estrogen receptor $\beta$ (erbeta), androgen receptor (ar), TH receptor $\alpha$ (tralpha), $\mathrm{TH}$ receptor $\beta$ (trbeta), deiodinases type 2 and 3 (dio2, dio3), ornithine decarboxylase (odc), arginine vasotocin (avt) and the reference gene ribosomal protein L8 ( $r$ pls) were measured as described in Langlois et al. [2010]. Real-time PCR primers for avt (forward: 5'-tggacgacgagagcgaaa-3'; reverse: 5'-cataagccgcagga- 
gaaagtc-3'; product size: $92 \mathrm{bp}$; primer concentration: $300 \mathrm{nM}$ each; annealing temperature: $58^{\circ} \mathrm{C}$ ) were also designed based on the complete sequence published in GenBank (accession no. XM_002936358) and primers were optimized following the protocol described in Langlois et al. [2010]. All the gene expression analyses were performed on eight individual brains per phenotype per treatment. The relative standard curve method was used to interpolate relative mRNA abundance of target and reference genes within each sample. The standard curves were generated using equal parts of cDNA from each sex and treatment. Reaction efficiencies were determined by the MxPro 4.0 software (Stratagene) using the slope of the standard curves and for all the genes efficiencies were $90-110 \%$ with $\mathrm{R}^{2} \geq 0.990$. The mRNA levels of the reference gene rpls did not change with either finasteride or fadrozole treatment (data not shown), therefore transcript level data are normalized to $\mathrm{rpl}$ l8 and are presented as fold changes relative to $\mathrm{EtOH}$-control males in the case of finasteride and to water-control males in the case of fadrozole.

\section{Aromatase Activity}

Aromatase activity was measured using a modified radiometric method optimized for amphibian tissue as described in Langlois et al. [2010]. Briefly, cyp19 activity was measured in pools of 2 to 4 brains of animals of the same sex (NF $60 ; n=2-5$ pools). Cofactor and ${ }^{3} \mathrm{H}$-androstenedione were first incubated for $30 \mathrm{~min}$ at $37^{\circ} \mathrm{C}$. After this pre-incubation, brains were sonicated in phosphate buffer and incubated for $80 \mathrm{~min}$ at $25^{\circ} \mathrm{C}$. Aromatase activity was determined by tritiated water release from the C-1 $\beta$ carbon atom of $1 \beta-{ }^{3} \mathrm{H}$-androstenedione during its conversion to estrogen. Tritiated water was extracted with a charcoal solution and radioactivity was counted. Aromatase activity is expressed as fmol ${ }^{3} \mathrm{H}_{2} \mathrm{O} / \mathrm{h} \cdot \mathrm{mg}$ protein.

\section{Statistical Analysis}

Data for all the genes and for cyp19 activity were first tested for normality and homogeneity of variance using the KolmogorovSmirnov and the Levene tests, respectively. When the assumptions were not met, the data were transformed as required (e.g., $\log _{10}$, square root) and re-tested for normality and homogeneity of variance. Data were analyzed by one-way analysis of variance (ANOVA) followed by Bonferroni's post-hoc test for multiple comparisons. When data failed to meet assumptions even after being transformed, the nonparametric Kruskal-Wallis test on ranks was used. Differences were accepted as significant when $\mathrm{p}<0.05$.

\section{Results}

The effects of the anti-androgen finasteride on sex steroid- and TH-related mRNA levels in the brain of S. tropicalis metamorphs are shown in figure 1. Chronic exposure to finasteride significantly increased cyp19 (1.7-fold; fig. 1B), eralpha (1.7-fold; fig. 1C), dio3 (3.8-fold; fig. 1E) and trbeta (2.2-fold; fig. $1 \mathrm{~F}$ ) in intersex individuals with respect to EtOH-exposed control males and control females. Transcript levels of ar and erbeta were also increased in finasteride-induced intersex compared to
Table 1. Comparison between brain and hepatic gene expression changes following a chronic exposure to finasteride $(25 \mu \mathrm{M})$ during Silurana tropicalis development

\begin{tabular}{|c|c|c|c|c|c|c|}
\hline \multirow[t]{2}{*}{ Genes } & \multicolumn{3}{|c|}{ Brain $^{\mathrm{a}}$} & \multicolumn{3}{|l|}{ Liver $^{\mathrm{b}}$} \\
\hline & male & female & intersex & male & female & intersex \\
\hline$a r$ & $1.3 \uparrow^{\mathrm{d}}$ & - & $1.2 \uparrow^{\mathrm{d}}$ & - & - & - \\
\hline srd5alpha1 & - & - & - & - & - & $1.9 \downarrow^{\mathrm{e}}$ \\
\hline srd5alpha2 & - & - & - & $31.8 \downarrow^{\mathfrak{C}}$ & $25.7 \downarrow^{C}$ & $36.5 \downarrow^{\mathfrak{c}}$ \\
\hline srd5alpha3 & - & - & - & - & - & - \\
\hline srd5beta & - & - & - & - & $3.9 \downarrow^{c}$ & $3.3 \downarrow^{\mathrm{c}}$ \\
\hline eralpha & - & - & $1.7 \uparrow^{c}$ & $4.1 \uparrow^{c}$ & $6.1 \uparrow^{c}$ & - \\
\hline erbeta & - & - & $1.6 \uparrow^{\mathrm{d}}$ & - & - & - \\
\hline cyp19 & - & - & $1.7 \uparrow^{c}$ & nd & nd & nd \\
\hline tralpha & - & - & - & - & - & - \\
\hline trbeta & $1.8 \uparrow^{c}$ & - & $2.2 \uparrow^{c}$ & $3.1 \uparrow^{c}$ & - & - \\
\hline dio2 & - & - & - & $4.8 \uparrow^{c}$ & - & $6.1 \uparrow^{c}$ \\
\hline dio3 & $2.3 \uparrow^{c}$ & - & $3.8 \uparrow^{c}$ & $3.9 \downarrow^{c}$ & - & $16.1 \downarrow^{c}$ \\
\hline$a v t$ & - & - & - & na & na & na \\
\hline$o d c$ & - & - & - & na & na & na \\
\hline
\end{tabular}

nd = Not detectable; na $=$ not available; $-=$ no changes .

Fadrozole did not affect any of the transcripts measured in the frog brain. Statistically significant fold changes (with respect to $\mathrm{EtOH}$-control males) are reported along with arrows indicating increase or decrease of mRNA levels.

${ }^{a}$ Gene expression results reported in this study.

${ }^{b}$ Duarte-Guterman et al. [2009].

${ }^{c}$ Different from both control males and females $(\mathrm{p}<0.05)$.

${ }^{d}$ Different from control males $(\mathrm{p}<0.05)$.

${ }^{\text {e }}$ Different from control females $(\mathrm{p}<0.05)$.

EtOH-exposed control females (1.2-fold; fig. 1A) and control males, respectively (1.6-fold; fig. 1D). Finasteride did not affect the transcriptional regulation of srd5alpha1, srd5alpha2, srd5alpha3, srd5beta, avt and odc, tralpha, and dio2 (table 1) and the activity of cyp19 (fig. 2B).

Exposure to the anti-estrogen fadrozole did not result in any changes in mRNA levels in the frog brain; however, cyp19 activity was almost completely inhibited (by approximately 93\%) in the brain of fadrozole-treated males, females and intersex compared to water-controls (fig. 2A). Results for eralpha, erbeta, cyp19 and avt are shown as examples in figure 3 . The remaining gene expression data for the fadrozole exposure (i.e., srd5alphal, srd5alpha2, srd5alpha3, srd5beta, ar, odc, tralpha, trbeta, dio2 and dio3) are not shown because there were no effects of treatment. No differences in mortality were observed between treated and control individuals after chronic exposure to either finasteride or fadrozole (data not shown). 
Fig. 1. Effects of finasteride on ar (A), cyp19 (B), eralpha (C), erbeta (D), dio3 (E) and trbeta (F) mRNA levels in NF60 Silurana tropicalis brains. Chronic exposures of $S$. tropicalis from NF12 to NF60 to either $0.05 \% \mathrm{EtOH}$ (control) or $25 \mu \mathrm{M}$ finasteride (delivered in $0.05 \% \mathrm{EtOH}$ ) were performed. The mRNA levels are expressed relative to the male control group and are normalized to the ribosomal protein L8 (rpl8) mRNA levels. Bars represent the mean mRNA level + SEM. Different letters indicate statistically significant differences between sex treatments (one-way ANOVA; $\mathrm{n}=8, \mathrm{p}<0.05)$. The scales of the $\mathrm{y}$ axis vary between graphs. ar: androgen receptor, cyp19: aromatase, dio3: deiodinase type 3, eralpha: estrogen receptor $\alpha$, erbeta: estrogen receptor $\beta$ and trbeta: thyroid hormone receptor $\beta$.

Fig. 2. Effects of fadrozole (A) and finasteride (B) on aromatase activity in the brain of NF60 S. tropicalis. Chronic exposures of S. tropicalis from NF12 to NF60 to $25 \mu \mathrm{M}$ finasteride (delivered in $0.05 \% \mathrm{EtOH}$ ) or $2 \mu \mathrm{M}$ fadrozole (delivered in water) were performed. Enzyme activity is expressed in $\mathrm{fmol} / \mathrm{h}$ normalized to total protein content $(\mathrm{mg})$. Bars represent the mean + SEM. Data were analyzed using one-way ANOVA $(2-4$ brains per sample; $\mathrm{n}=2-5$; $\mathrm{p}<$ 0.01). Different letters indicate statistically significant differences between sex treatments.
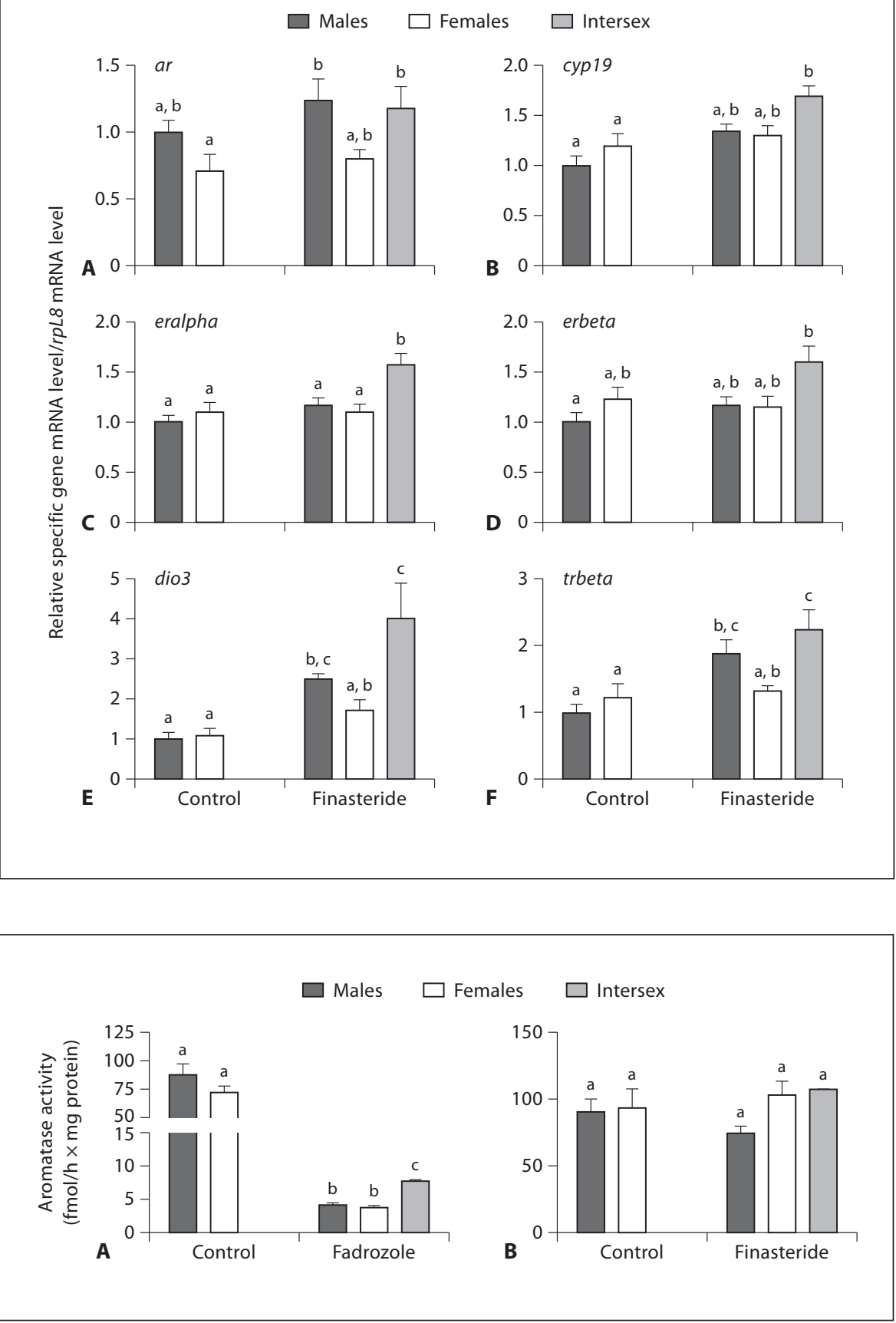

\section{Discussion}

Our previous work showed that chronic exposures to anti-androgen or anti-estrogen chemicals altered sex ratios in S. tropicalis [Duarte-Guterman et al., 2009]. Gonadal histology demonstrated that $27 \%$ male, $53 \%$ female and $20 \%$ intersex individuals were produced after finasteride treatment, and 55\% male, $30 \%$ female and $15 \%$ intersex individuals were obtained after fadrozole treatment. The water and EtOH controls exhibited 53\% male, $47 \%$ female individuals, and $54 \%$ male, $46 \%$ female individuals, respectively. We used hepatic profiles of tran- 
Fig. 3. Effects of fadrozole on eralpha (A), erbeta (B), cyp19 (C), and avt (D) mRNA levels in NF60 Silurana tropicalis brains. Chronic exposures of $S$. tropicalis from NF12 to NF60 to either water (control) or $2 \mu \mathrm{M}$ fadrozole were performed. The mRNA levels are expressed relative to the male control group and are normalized to the ribosomal protein L8 (rpls) mRNA levels. Bars represent the mean mRNA level + SEM. Different letters indicate statistically significant differences between sex treatments (one-way ANOVA; $\mathrm{n}=8, \mathrm{p}<0.05$ ). avt: arginine vasotocin, cyp19: aromatase, eralpha: estrogen receptor $\alpha$, erbeta: estrogen receptor $\beta$.

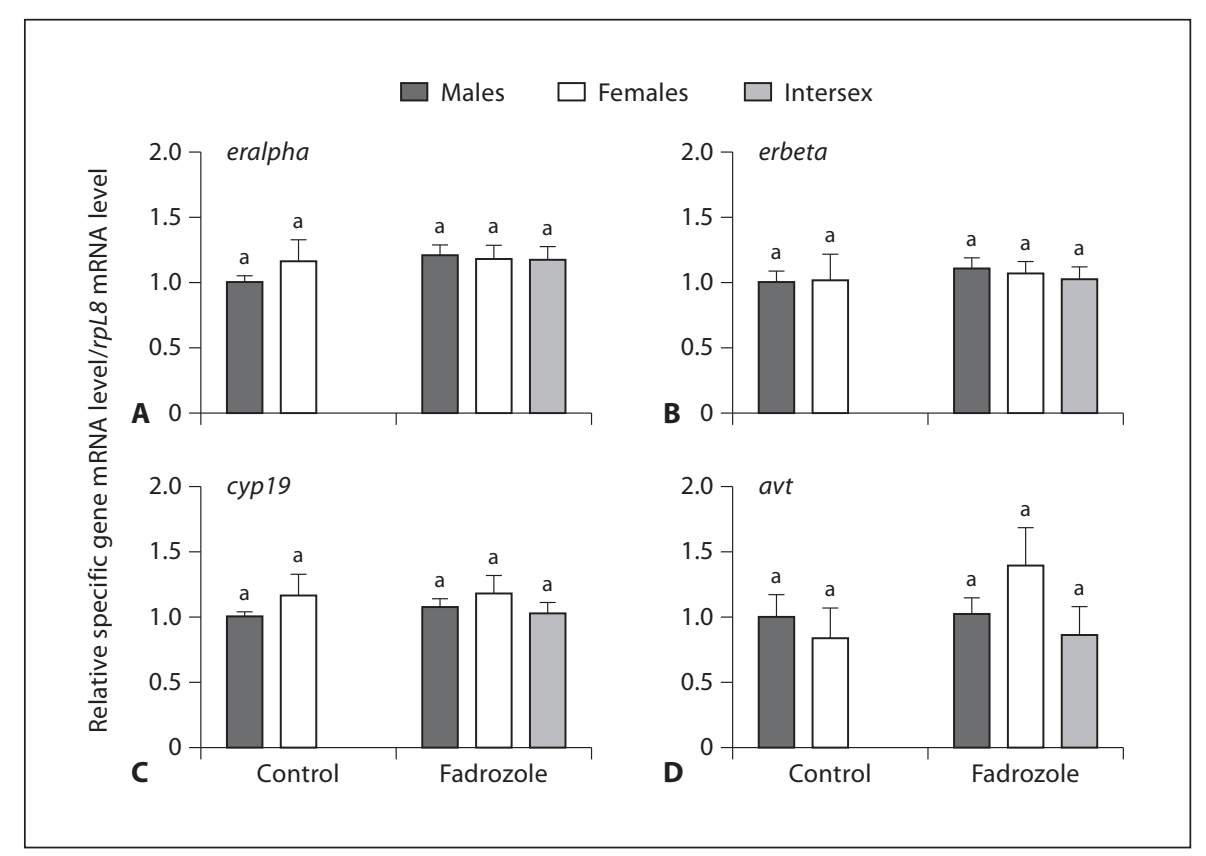

script levels to show that the physiological status of normal and intersex tadpoles is different [Duarte-Guterman et al., 2009]. Here we extend these observations to the developing brain.

In the frog brain, waterborne exposure to the antiandrogen finasteride altered the mRNA levels of sex steroid- and TH-related genes while the anti-estrogen fadrozole did not induce any changes in transcriptional regulation for any of the analyzed genes. Finasterideinduced intersex tadpoles exhibited increases in the levels of the three sex steroid receptor (ar, eralpha and erbeta) mRNAs and the estrogen synthesis enzyme cyp19 $m R N A$ in the brain. There is very limited information regarding the regulation of our target genes after finasteride treatment in vertebrates. However, it has been demonstrated in humans that one consequence of finasteride treatment is an increase in plasma testosterone [Habib et al., 1997; Roehrborn et al., 2003]. This increase would provide potential substrate for cyp19 to produce $17 \beta$-estradiol which in turn could autoregulate the transcription of its own steroidogenic enzyme and its receptors (due to the presence of an estrogen-responsive element in the promoter region of these genes in many species including frogs) [Katzenellenbogen, 1996; Akatsuka et al., 2005]. We propose that the increase in mRNA levels of the estrogen-related genes in the frog brain measured in our study could be explained by a putative increase in testosterone level in the brain. Finasteride did not affect srd5alpha (type 1,2,3) and srd5beta mRNAs in the brain which contrasts with the effects in livers of the same animals. Finasteride significantly decreased hepatic srd5alpha2 and srd5beta mRNA levels in metamorphic S. tropicalis tadpoles (NF 60) [Duarte-Guterman et al., 2009] and in whole larvae (NF 46) [Langlois et al., 2010]. Interestingly, the transcriptional regulation of srd5alpha3 mRNA was not affected by finasteride treatment in $S$. tropicalis in any tissue or developmental stage studied [NF 60 brain, present study; NF 60 liver Duarte-Guterman et al., 2009; NF 46 whole larvae Langlois et al., 2010]. Srd5alpha3 is a newly discovered enzyme and its regulation and function have not yet been fully explored [Tamura et al., 2007; Uemura et al., 2008], especially not in frogs. Therefore, there is a possibility that srd5alpha 3 may be differentially affected by finasteride or differentially regulated compared to srd5alpha1 and srd5alpha2. To our knowledge, this is the first study assessing the effects of finasteride on srd5alpha3 mRNA levels in the amphibian brain.

Finasteride treatment also increased brain trbeta and dio3 mRNA levels in treated males and intersex animals. During metamorphosis, as TH levels rise, and after treatment with T3, trbeta and dio3 mRNA increase in the brain [Morvan Dubois et al., 2006; Hogan et al., 2007; Wang et al., 2008]. Our results suggest that an inhibition of srd5alpha (type 1,2,3) and srd5beta would favor an increase in TH levels in the brain. Based on these data, we can speculate that there is an interaction between the androgen and $\mathrm{TH}$ axes, and this is supported by three other studies. Hy- 
pothyroid rats exhibit decreased hepatic srd5alpha1 transcript level and activity; while T4 addition restores both srd5alphal mRNA level and activity [Ram and Waxman, 1990]. Furthermore, S. tropicalis larvae (NF 52-54) treated with T3 exhibit increased brain srd5alpha1 and srd5alpha2 mRNA levels [Duarte-Guterman and Trudeau, 2010]. Finally, chronic exposure to finasteride in S. tropicalis results in a hepatic increase in the transcript level of the enzyme involved in the activation of $\mathrm{TH}$ (dio2) but in a reduction of the mRNA level of the enzyme responsible for TH inactivation (dio3; NF 60) [Duarte-Guterman et al., 2009]. However, the precise relationship and physiological consequences of cross-talk between the androgen and $\mathrm{TH}$ axes remains to be determined.

When comparing the brain and hepatic profiles of transcript levels in finasteride-induced intersex individuals in S. tropicalis (table 1), our data support the evidence that intersex animals express a different endocrine physiology when compared to non-exposed males and females. Furthermore, there is a clear difference in tissue sensitivity in response to finasteride between brain and liver frog tissues which adds to the complexity of the intersex pathophysiology (table 1).

In contrast to finasteride, fadrozole did not affect the transcriptional regulation of any of the genes analyzed. This is in marked contrast with previous studies on S. tropicalis liver [Duarte-Guterman et al., 2009] and fish brain [Villeneuve et al., 2009; Zhang et al., 2009] that have shown that fadrozole affects mRNA levels of many genes. Interestingly, we found that cyp19 activity was almost completely inhibited in the brain of fadrozole-treated animals compared to controls; while none of the estrogenresponsive genes were affected (cyp19, eralpha, erbeta and $a v t$ ). Research from our laboratory has shown that exposure to the synthetic estrogen, ethinylestradiol increases the transcript levels of estrogen-responsive genes, i.e., cyp19 and eralpha, in the frog brain [Duarte et al., 2006]. However, the fadrozole-induced decline in estrogen levels does not appear to have the opposite effect of an estrogen exposure since no transcriptional changes were observed in our study. Future studies should investigate other endpoints (e.g., brain morphology, sex steroid levels, and other transcripts) in more specific areas of the brain to understand the consequences of a lack of estrogen during amphibian development. Indeed, recent studies have demonstrated that estrogens are critical for neuronal development [Diotel et al., 2010]. Furthermore, we observed a 2-fold difference in cyp19 activity levels in the brain between the fadrozole induced-intersex and the treated males and females. This difference in response between intersex and differentiated males and females (both fadrozole treated and control) was also observed in the hepatic profiles of mRNA levels of the same animals [DuarteGuterman et al., 2009] supporting the idea that intersex animals are different from both normal, untreated animals, and males and females from the treatment groups.

Studies in many vertebrate species have shown that avt is an important neuropeptide regulating social behaviors such as vocalization, parental and sexual behaviors [reviewed in Goodson and Bass, 2001]. In amphibians, avt regulates reproductive behaviors (e.g., amplectic clasping of females and release calls) [Moore and Miller, 1983]. In this study, we used avt in the brain as an endpoint to assess whether this neuropeptide could be affected in intersex and sex-reversed individuals after exposure to fadrozole or finasteride. Expression of avt was not affected after exposure to either chemical. In adult amphibians, concentrations of avt are higher in certain brain regions in males relative to females [Boyd and Moore, 1992; Boyd et al., 1992]. However, in the brains of our control groups, avt did not show dimorphic expression which suggests that sex-specific regulation by avt may not be fully in place at the end of metamorphosis. Future research should investigate specific brain regions and the long-term consequences of sex steroid synthesis inhibition on the avt system and other related endpoints in the tadpole brain.

In conclusion, exposures to finasteride and fadrozole resulted in very distinct profiles of gene expression in the brains of $S$. tropicalis. We showed that finasteride-induced intersex animals were distinguishable from normal males and females in the EtOH-control groups. On the other hand, mRNA levels in the brain of fadrozoleinduced intersex individuals were similar to normal males and females. Although gonads of finasteride- and fadrozole-induced intersex animals are morphologically similar, 'intersex' is a heterogeneous condition which according to the chemical mode of action leads to different endocrine pathophysiologies. Whether chemically-induced differences in gene expression in the brain lead to developmental and reproductive abnormalities remains to be further elucidated. Finally, this study supports evidence of a crosstalk between the androgen and TH systems in amphibians.

\section{Acknowledgements}

This research was supported by the NSERC-DG program (to V.L.T.), the NSERC-PGSM and PGSD programs (to V.S.L.) and NSERC-PGSD program (to P.D.-G.). Fadrozole was provided as a gift from Novartis Pharma AG. 


\section{References}

Akatsuka N, Komatsuzaki E, Ishikawa A, Suzuki I, Yamane N, Miyata S: Expression of the gonadal p450 aromatase gene of Xenopus and characterization of the $5^{\prime}$-flanking region of the aromatase gene. J Steroid Biochem Mol Biol 96:45-50 (2005).

-Ankley GT, Kahl MD, Jensen KM, Hornung MW, Korte JJ, Makynen EA, Leino RL: Evaluation of the aromatase inhibitor fadrozole in a short-term reproduction assay with the fathead minnow (Pimephales promelas). Toxicol Sci 67:121-130 (2002).

$\checkmark$ Bernal J, Guadano-Ferraz A, Morte B: Perspectives in the study of thyroid hormone action on brain development and function. Thyroid 13:1005-1012 (2003)

-Boyd SK, Tyler CJ, De Vries GJ: Sexual dimorphism in the vasotocin system of the bullfrog (Rana catesbeiana). J Comp Neurol 325:313325 (1992).

Boyd SK, Moore FL: Sexually dimorphic concentrations of arginine vasotocin in sensory regions of the amphibian brain. Brain Res 588 : 304-306 (1992).

Diotel N, Page Y L, Mouriec K, Tong SK, Pellegrini E, et al: Aromatase in the brain of teleost fish: Expression, regulation and putative functions. Front Neuroendocrinol 31: 172-92 (2010).

Duarte P, Hogan NS, Lean DRS, Trudeau VL: \#559. Regulation and endocrine disruption of aromatase in the brain of developing Rana pipiens. 27th Annual Meeting of the Society of Environmental Toxicology and Chemistry of North America, Montreal, PQ, Canada (2006).

Duarte-Guterman P, Langlois VS, Hodgkinson K, Pauli BD, Cooke GM, Wade MG, Trudeau VL: The aromatase inhibitor fadrozole and the 5-reductase inhibitor finasteride affect gonadal differentiation and gene expression in the frog Silurana tropicalis. Sex Dev 3: 333-341 (2009).

Duarte-Guterman P, Trudeau VL: Regulation of thyroid hormone-, oestrogen- and androgen-related genes by triiodothyronine in the brain of Silurana tropicalis. J Neuroendocrinol 22:1023-1031 (2010).

Goodson JL, Bass AH: Social behavior functions and related anatomical characteristics of vasotocin/vasopressin systems in vertebrates. Brain Res Rev 35:246-265 (2001).

-Habib FK, Ross M, Tate R, Chisholm GD: Differential effect of finasteride on the tissue androgen concentrations in benign prostatic hyperplasia. Clin Endocrinol (Oxf) 46:137144 (1997).

- Hayes T, Khoury V, Narayan A, Nazir M, Park A, et al: Atrazine induces complete feminization and chemical castration in male African clawed frogs (Xenopus laevis). Proc Natl Acad Sci USA 107:4612-4617 (2010).
Hayes TB: Sex determination and primary sex differentiation in amphibians: genetic and developmental mechanisms. J Exp Zool 281: 373-399 (1998).

Hayes TB, Haston K, Tsui M, Hoang A, Haeffele C, Vonk A: Atrazine-induced hermaphroditism at $0.1 \mathrm{ppb}$ in American leopard frogs (Rana pipiens): laboratory and field evidence. Environ Health Perspect 111:568-575 (2003).

Hogan NS, Crump KL, Duarte P, Lean DRS, Trudeau VL: Hormone cross-regulation in the tadpole brain: Developmental expression profiles and effect of T3 exposure on thyroid hormone-and estrogen-responsive genes in Rana pipiens. Gen Comp Endocrinol 154:515 (2007)

Hutchison JB, Steimer T: Brain 5-beta-reductase - a correlate of behavioral sensitivity to androgen. Science 213:244-246 (1981).

Katzenellenbogen BS: Estrogen receptors: bioactivities and interactions with cell signaling pathways. Biol Reprod 54:287-293 (1996).

Langlois VS, Duarte-Guterman P, Ing S, Pauli BD, Cooke GM, Trudeau VL: Fadrozole and finasteride exposures modulate sex steroidand thyroid hormone-related gene expression in Silurana (Xenopus) tropicalis early larval development. Gen Comp Endocrinol 166:417-427 (2010).

McCoy KA, Bortnick LJ, Campbell CM, Hamlin HJ, Guillette LJ, St Mary CM: Agriculture alters gonadal form and function in the toad Bufo marinus. Environ Health Perspect 116: 1526-1532 (2008).

Martiniuk CJ, Xiong HL, Crump K, Chiu S, Sardana $R$, et al: Gene expression profiling in the neuroendocrine brain of male goldfish (Carassius auratus) exposed to 17 alphaethinylestradiol. Physiol Genomics 27:328336 (2006).

-Mennigen JA, Martyniuk CJ, Crump K, Xiong HL, Zhao E, et al: Effects of fluoxetine on the reproductive axis of female goldfish (Carassius auratus). Physiol Genomics 35:273-282 (2008).

Moore FL, Miller LJ: Arginine vasotocin induces sexual behavior of newts by acting on cells in the brain. Peptides 4:97-102 (1983).

Morris J A, Jordan CL, Breedlove SM: Sexual differentiation of the vertebrate nervous system. Nat Neurosci 7:1034-1039 (2004).

Morvan Dubois G, Sebillot A, Kuiper GG, Verhoelst CH, Darras VM, Visser TJ, Demeneix BA: Deiodinase activity is present in Xenopus laevis during early embryogenesis. Endocrinology 147:4941-4949 (2006).

Nieuwkoop P, Faber J: Normal Table of Xenopus laevis (Daudin) (Garland Publishing, Inc., New York, 1994).
Olmstead AW, Kosian PA, Korte JJ, Holcombe GW, Woodis KK, Degitz SJ: Sex reversal of the amphibian, Xenopus tropicalis, following larval exposure to an aromatase inhibitor. Aquat Toxicol 91:143-150 (2009).

Ottinger MA, Lavoie ET, Abdelnabi M, Quinn MJ, Marcell A, Dean K: An overview of dioxin-like compounds, $\mathrm{PCB}$, and pesticide exposures associated with sexual differentiation of neuroendocrine systems, fluctuating asymmetry, and behavioral effects in birds. J Environ Sci Health Part C 27:286-300 (2009).

Ram PA, Waxman DJ: Pretranslational control by thyroid hormone of rat liver steroid 5 alpha-reductase and comparison to the thyroid dependence of two growth hormoneregulated CYP2C mRNAs. J Biol Chem 265: 19223-19229 (1990).

- Roehrborn CG, Lee M, Meehan A, Waldstreicher J: Effects of finasteride on serum testosterone and body mass index in men with benign prostatic hyperplasia. Urology 62:894899 (2003).

Steele RE, Mellor LB, Sawyer WK, Wasvary JM, Browne LJ: In vitro and in vivo studies demonstrating potent and selective estrogen inhibition with the nonsteroidal aromatase inhibitor CGS 16949A. Steroids 50:147-161 (1987).

Stoner E: The clinical development of a 5 alphareductase inhibitor, finasteride. J Steroid Biochem Mol Biol 37:375-378 (1990).

Tamura K, Furihata M, Tsunoda T, Ashida S Takata R, et al: Molecular features of hormone-refractory prostate cancer cells by genome-wide gene expression profiles. Cancer Res 67:5117-5125 (2007).

Uemura M, Tamura K, Chung S, Honma S, Okuyama A, Nakamura Y, Nakagawa $\mathrm{H}$ : Novel 5 alpha-steroid reductase (SRD5A3, type-3) is overexpressed in hormone-refractory prostate cancer. Cancer Sci 99:81-86 (2008)

Villeneuve L, Wang RL, Bencic DC, Biales AD, Martinovic D, et al: Altered gene expression in the brain and ovaries of zebrafish (Danio rerio) exposed to the aromatase inhibitor fadrozole: microarray analysis and hypothesis generation. Environ Toxicol Chem 28: 1767-1782 (2009).

-Wang XD, Matsuda H, Shi YB: Developmental regulation and function of thyroid hormone receptors and 9-cis retinoic acid receptors during Xenopus tropicalis metamorphosis. Endocrinology 149:5610-5618 (2008).

-Zhang D, Popesku JT, Martyniuk CJ, Xiong H, Duarte-Guterman P, et al: Profiling neuroendocrine gene expression changes following fadrozole-induced estrogen decline in the female goldfish. Physiol Genomics 38: 351-361 (2009). 